\title{
Periodontal Emotional Stress Syndrome: Review of Basic Concepts, Mechanism and Management
}

\author{
Jyoti Bansal1* ${ }^{*}$ Abhishek Bansal'2, Mohit Shahi' ${ }^{3}$, Suresh Kedige ${ }^{4}$, Rachita Narula4 \\ ${ }^{1}$ Department of Periodontics, MM College of Dental Sciences and Research, Mullana, India \\ ${ }^{2}$ Department of Endodontics, MM College of Dental Sciences and Research, Mullana, India \\ ${ }^{3}$ Department of Pathology, School of Medicine, Taylor's University, Subang Jaya, Malaysia \\ ${ }^{4} \mathrm{MM}$ College of Dental Sciences and Research, Mullana, Ambala, India \\ Email: ${ }^{*}$ drjyo17@yahoo.co.in
}

Received 3 March 2014; revised 3 April 2014; accepted 10 April 2014

Copyright (C) 2014 by authors and Scientific Research Publishing Inc.

This work is licensed under the Creative Commons Attribution International License (CC BY). http://creativecommons.org/licenses/by/4.0/

(c) (i) Open Access

\begin{abstract}
Stress is an unavoidable consequence of life. It is described as adverse emotions or reactions to unpleasant experiences. Thus, stress can be viewed as a process with both psychological and physiological components. The possible mechanisms by which psychosocial factors act on periodontal tissues are oral hygiene negligence, changes in dietary intake, smoking, bruxism, gingival circulation, alteration in salivary component and flow, hormonal changes and lowered host resistance. During stress hypothalamic-pituitary-adrenal (HPA) axis and the sympathetic nervous system interact and release glucocorticoid which has myriad of effects that disrupt homeostasis and lead to increased susceptibility to periodontal diseases. The dental practioner, thus, may always decide to refer patients to appropriate professional for assistance and counselling. Therefore, reducing stress and improving coping strategies may improve the periodontal prognosis and treatment outcomes. The aim of this review is to provide an insight into the relationship between psychological stress and periodontal diseases.
\end{abstract}

\section{Keywords}

Periodontal Disease, Psychosocial Factors, Stress, Stress Management

\section{Introduction}

The term stress, when used in layman terms, describes an adverse emotions or reactions to unpleasant experi-

*Corresponding author.

How to cite this paper: Bansal, J., Bansal, A., Shahi, M., Kedige, S. and Narula, R. (2014) Periodontal Emotional Stress Syndrome: Review of Basic Concepts, Mechanism and Management. Open Journal of Medical Psychology, 3, $250-261$.

http://dx.doi.org/10.4236/ojmp.2014.33026 
ences. Stress is regarded as a cognitive perception of uncontrollability and/or unpredictability that is expressed in a physiological and behavioral response [1]. Thus, stress can be viewed as a process with both psychological and physiological components.

In 1976, Seyle [2] was basically responsible for defining stress as the response state of an organism to physical and mental forces beyond the adaptive capacity that lead to diseases of adaptation and eventually to exhaustion and death. He recognized stressors which act to produce positive changes in the body (e.g. exciting, pleasurable), leading to a response state which he defined as "eustress", or stressors could be negative that induce, threatening homeostasis with pain, discomfort and physical pathology. He defined the negative response state as "distress".

According to Breivik (1996) [3] stress is not what happens to someone, but how someone reacts to what happens. He defines stress as the psychophysiological response of an organism to perceived threat or challenge.

Periodontal diseases are defined as inflammatory diseases caused by pathogenic microflora organised in biofilms surrounding the teeth resulting in destruction of teeth-supporting tissues that can lead to tooth loss. Although bacteria plays an essential role it seems to be insufficient to explain occurrence or progression of the disease. There are several factors such as age, tobacco use, systemic diseases and psychological stress that have been identified as important risk factors for periodontitis.

De Marco (1976) [4] coined the term "Periodontal Emotional Stress Syndrome" for individuals with severe periodontitis who had emotional stress associated with active service in Vietnam suggesting a role of occupational stress in the progression of periodontitis.

The aim of this review is to provide an insight into psychological stress pathways and how stress mechanisms may modify the progression and outcome of periodontal disease and importance of stress management in recuperating the treatment outcome.

\section{Pathophysiology of Stress Response}

Psychosocial stress can affect the periodontal tissues directly through biological mechanism and indirectly through the changes in life-style such as ignoring oral-hygiene measures, smoking more heavily and consuming more fat and sugar in Diet [5]. Hence, there are two proposed mechanistic links: one biological and the other behavioural [6].

The biological mechanism emphasizes how stress and depression can reduce immune system function and facilitate chronic inflammation. Whereas, in physiological response to stress, the hypothalamus-pituitary-adrenal cortex (HPA) axis is stimulated that leads to secretion of corticotropin-releasing factor and vasopressin from anterior hypothalamus, which act on the hypophysis. The pituitary gland, in turn, releases adrenocorticotrophic hormone, which acts on the adrenal cortex and increases production and release of cortisol and glucocorticoid hormones. The glucocorticoids then reduces immunocompetence through myriad of effects including,

- Suppression of the inflammatory response.

- Inhibiting immunoglobulin $\operatorname{IgA}, \operatorname{IgG}$ and neutrophil function which leads to increased biofilm colonization and reduced ability to prevent connective tissue invasion.

- Modification of cytokine profiles primarily interleukin-1 and TNF $\alpha$.

- Elevation of blood glucose levels.

- Altering the levels of certain growth factors.

Additionally, after periods of chronic elevation, cortisol loses its ability to inhibit inflammatory responses initiated by immune reactions, which leads to chronic inflammatory destruction within the periodontium. The autonomic nervous system also gets activated to induce release of adrenaline from the adrenal medulla, while various neuropeptides such as substance $\mathrm{P}$ are released from sensory nerve fibers [7]. Under ideal circumstances these factors function in harmony to enable the organism to ward off the stressful event and maintain homeostasis (Figure 1).

The behavioural mechanism emphasizes that people suffering from stress and depression may increase poor health behaviours, such as smoking or drinking more frequently, consuming an unhealthy diet and neglecting their oral hygiene. This leads to increased oral biofilm burden and decreased resistance of the periodontium to inflammatory breakdown. In an early study, adult subjects under financial strain and exhibiting poor coping behaviours were reported to be at increased risk for severe periodontitis [8]. Periodontitis patients with inadequate stress behaviours strategies (defensive coping) were suggested to be at higher risk for severe periodontal diseases [9]. 


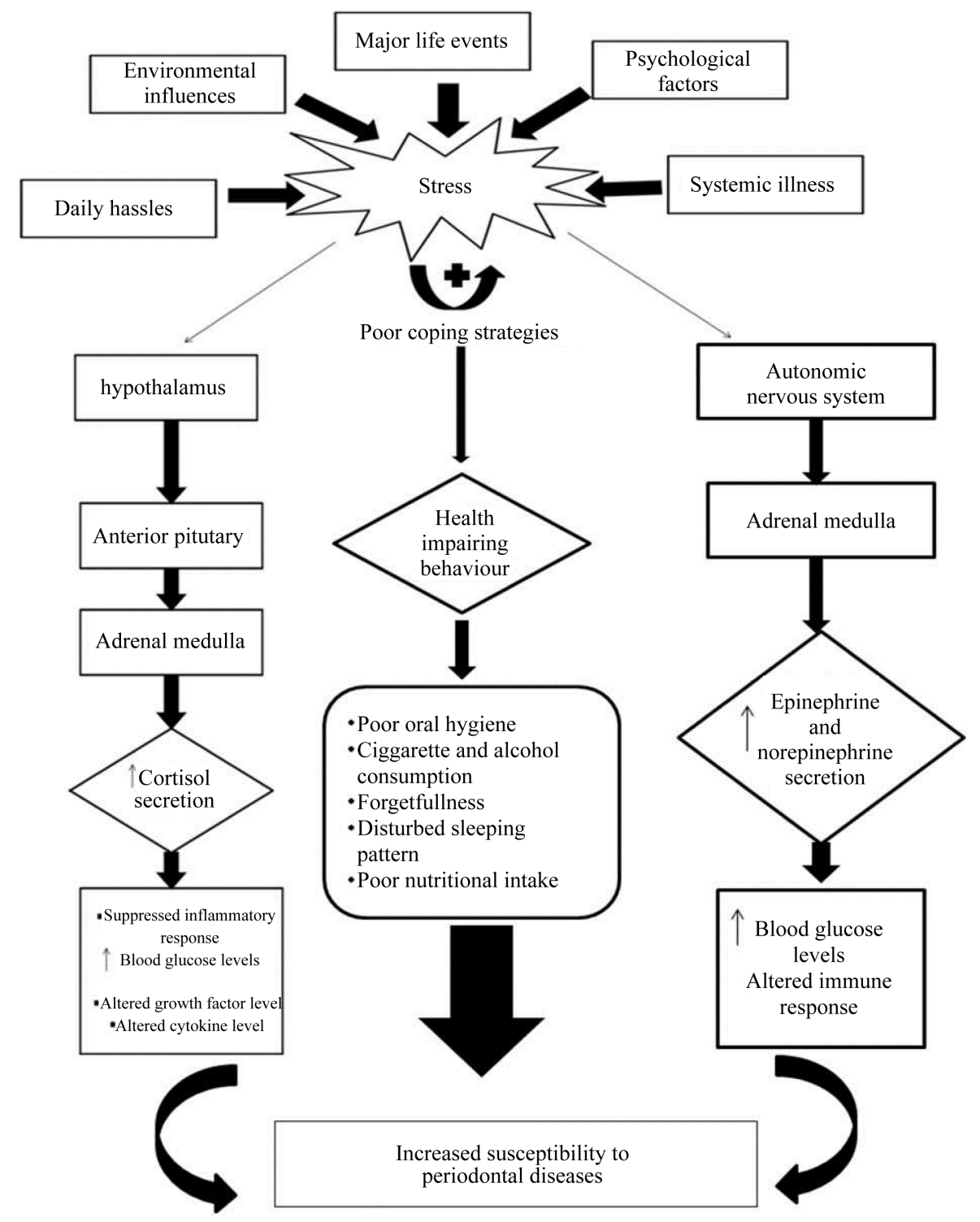

Figure 1. Pathophysiology of stress response and its influence on periodontium ${ }^{5}$.

Despite numerous clinical and epidemiological studies that confirmed an association between psychological stress and periodontitis, biological mechanisms involved are not fully understood [10]-[12].

\section{Discussion}

\subsection{Influence of Stress on Periodontium}

Stress is regarded as a cognitive perception of uncontrollability and/or unpredictability that is expressed in a physiological and behavioural response [1]. Stress is often classified as acute and chronic types. Acute stress lasts for a period of minutes to hours, whereas chronic stress persists for several hours, a day, weeks or even months. In case of acute stress, stress response may prepare the immune system for challenges such as infection that may be imposed by the stressor [13]. When stress becomes chronic, it may influence inflammatory processes leading to development of systemic or local diseases such as rheumatoid arthritis [14], diabetes [15], cardiovascular diseases [16] or periodontal diseases [17].

An association between stress and periodontal disease was suggested over 50 years ago and has subsequently been supported by numerous studies. The first prospective longitudinal study for one year was conducted by 
Freeman and Goss (1993) [18] to investigate a relationship between stress and changes in periodontal status. The study concluded that oral hygiene negligence was related to increase in periodontal attachment loss. The most recent literature on the relationship between stress, depression and periodontal disease are significant because they address critical areas of interest surrounding an important perio-systemic connection [10] [19]-[21].

Numerous studies have also reported an increased susceptibility to systemic diseases and delayed wound healing in both animals and humans who are subjected to chronic physical or emotional stress [22]. The mediating effect of chronic stress on periodontium can be explained by diminished immune response which causes release of local neuropeptides such as substance $\mathrm{P}$ and neurokinin A, that may provide a mechanism for neural modification of inflammatory changes in the periodontium [3] [23].

The possible mechanisms by which psychosocial factors act on periodontal tissues are oral hygiene negligence, changes in dietary intake, smoking, bruxism, changes in gingival circulation, alteration in salivary flow and components, endocrine hormonal changes and lowered host resistance [24]. For example, individuals who smoked, had inadequate dietary habits, consumed alcohol or were physically inactive tended to be more irregular tooth brushers. It is reasonable to assume that such individuals are affected by anxiety or depression and poor coping skills. Harmful effects that result from psychic influence on the organic control of tissues are known as psychosomatic disorders. There are two ways, in which psychosomatic disorder may be induced in the oral cavity:

1) Through the development of habits that are injurious to the periodontium.

2) By the direct effect of the autonomic nervous system on the physiologic tissue balance.

Moreover, personality types, mental stability status, psychological disorders, lifestyle, variations in locus of control and coping style may alter the effects of stress. Harmful effects of stress in humans have been associated with undesirable life events such as financial and occupational strain, perceived ill health, loss of a spouse or loved one, academic strain, low socioeconomic status, low level of education, military combat, excessive noise, and marital difficulties.

\subsection{Stress and Physiological Changes}

\section{Alterations in Salivary Flow and Components}

Psychosocial stress or emotional disturbances produce a transient reduction in salivary flow and changes in the salivary components. Saliva in turn, relates to plaque formation, calculus deposition, and antibacterial and proteolytic activities, all of which may have a bearing on periodontal disease. Blood and saliva can be used to monitor the systemic as well as the oral health status [25]. Furthermore, stress is also a factor that can be followed by analysis of saliva, especially by determining the levels of stress-related markers [26]. These markers have biological properties that influence genesis and development of periodontal diseases. There are numerous stressrelated molecules involved in different aspects of stress response.

1) Cortisol

Cortisol is a well-known stress-related hormone that can be detected in blood, saliva and gingival crevicular fluid (GCF) [27] [28]. Salivary level of cortisol reliably reflects HPA axis activity and is used in human psychological studies as a biological marker of stress [29]. Cortisol acts as an anti-inflammatory and immunosuppressive hormone by inhibiting the formation of $\mathrm{T}$ lymphocytes and suppressing the function of natural killer cells (NK) or macrophages [30] [31]. In addition to these effects, it induces an increase in blood sugar concentration and influences fat metabolism [32]. Recently, salivary-free cortisol was suggested to offer advantages over serum cortisol [33].

2) Catecholamines

Catecholamines relay information from the CNS to the immune system [34]. Catecholamines modulate a wide range of immune functions, including cell proliferation, inhibition of proinflammatory cytokines such as interferon gamma (IFN- $\alpha$ ), interleukin-2 (IL-2), interleukin-6 (IL-6) as well as interleukin-12 (IL-12) and tumour necrosis factor-alpha (TNF- $\alpha$ ) [35], suppression of lymphocyte proliferation, NK activity [36], antibody production and cytolytic activity [37]. Salivary catecholamines are elevated by psychological stress factors and serves as a useful index of sympathetic adrenomedullary system activity (SAM) [38].

3) Chromogranin A

Chromogranin A has the potential to act as a useful index of psychological stress [39] since it is secreted from the adrenal medulla and sympathetic nerve endings as well as by serous and ductal cells of human submandibu- 
lar gland. Thus, it is considered to be a sensitive and important index of SAM and a nnovel stress marker in the saliva [40] [41].

4) Neuropeptides

Neuropeptides such as Substance P is important in initiating and sustaining inflammation, increasing pro-inflammatory cytokine production and by limiting the production of transforming growth factor-b (TGF-b) and interferon gamma (IFN-c) activated macrophages [42].

These markers generally act as hormonal mediators and play a role in the ability of stress to promote diseases by influencing the host response [43].

5) Stress and Lowered Host Resistance

Periodontal diseases are inflammatory diseases associated with local and systemic elevations of pro-inflammatory cytokines such as TNF-a, IL-6 and prostaglandins and result in tissue destruction by the contribution of MMPs [44] [45]. Stress impairs the balance between pro-inflammatory and anti-inflammatory responses. The relationship between stress and periodontal diseases might be mediated by alterations in GCF IL-1, IL-6 levels and reduction in polymorphonuclear leucocyte chemotaxis and phagocytosis and reduced proliferation of lymphocytes [46].

Psychosocial stress stimulates the brain where its stimulation or inhibition is dependent on adaptive and maladaptive coping respectively. On stimulation, the autonomic nervous system leads to prostaglandins and proteases secretion that leads to periodontal disease progression. The hypothalamo-pituitary-adrenal axis (HPA) leads to a production of glucocorticoids (cortisol) that depresses the immune system by diminishing the IgA and IgG secretions thereby enhancing the periodontal disease progression and poor treatment response [47]. Subsequently, this process could increase vulnerability of periodontal tissues to pathogenic microorganisms by activation of cellular responses leading to local tissue destruction [48].

Patients suffering from periodontitis who are under stressful conditions have increased levels of IL-6 [49] and IL-1b [50] in GCF, and similarly, patients with aggressive forms of periodontitis have elevated levels of IL-6 and IL- $1 \mathrm{~b}$ in serum. On the contrary, another study failed to find any correlation between IL- 6 and IL- $1 \mathrm{~b}$ and cortisol levels in peripheral blood of aggressive forms of patients with periodontitis [51].

A number of studies have investigated the effects of circadian rhythm on the stress-related markers such as cortisol. Cortisol has increased concentrations towards the early hours of the morning peaking shortly after awakening and decreasing concentrations over the day and lowest at night [52].

\subsection{Stress and Behaviour Changes}

Stress influence the consequences of behavioural patterns, extending from negligence of oral hygiene to dietary inadequacies, poor sleep patterns, use of tobacco products, alcohol consumption that contribute to the "vicious cycle" of increasingly severe forms of advanced periodontal inflammation and disease.

1) Oral hygiene negligence and stress

It is obvious that proper oral hygiene is partially dependent on the mental health status of the patient. Some patients may be disturbed or distracted psychologically so that personal hygiene is neglected. Other patients may intentionally ignore oral hygiene to fulfill deep neurotic needs.

2) Changes in dietary intake

Emotional conditions are thought to modify dietary intake, thus indirectly affecting periodontal status. This can involve for instance, the consumption of excessive quantities of refined carbohydrates and softer diets, requiring less vigorous mastication and therefore predisposing to plaque accumulation at the proximal risk sites.

3) Parafunctional habits

One classical hypothesis for the role of stress in periodontal diseases was directly caused by bruxism and clenching that directly led to loss of periodontal attachment apparatus in the absence of other factors. Bruxism can occur as brief, rhythmic strong contractions of the jaw muscles during eccentric lateral jaw movement or in maximum intercuspation, which is called clenching. The patient may be completely unaware of these repeated and sustained forced contacts of the teeth that seem to have no functional significance in humans. Certain types of individuals seem to be predisposed to bruxism. Olkinuera (1972) [53] divided bruxers into 2 categories,

a) Those associated with stressful events and

b) Those without any association of stress.

There is little evidence to suggest that bruxists have personality derangement or mental illness. But it has been 
proved that brain-damaged children and mentally retarded individuals have a higher prevalence for bruxism.

4) Use of tobacco and its products

Understanding the cytotoxic effects of tobacco use and nicotine dependence is essential for adequate patient management. Nicotine is a highly psychoactive tertiary amine. Chronic exposure to nicotine stimulates release of dopamine into the central nervous system (CNS), neuronal cleft, and other sites and proliferation of nicotinic acetylcholine receptors on postsynaptic neurons. Brain metabolism initially increases and then stabilizes in the presence of nicotine. With repeated exposure, CNS stimulation by nicotine gradually wanes and the presence of nicotine becomes necessary to ward off withdrawal symptoms. Nicotine dependence is not only a "risk factor" for other diseases, but is a disease requiring treatment in its own right.

\subsection{Psychosocial Stress and Periodontal Diseases}

1) Stress and Gingivitis

Gingivitis is the organism's response to persistent microbial plaque and is characterized by a well-established inflammation affecting the superficial gingival connective tissue [54]. Stress diminishes the salivary flow and increases the dental plaque formation which leads to gingival inflammation. A group of authors analyzed the effects of psychological stress on local proinflammatory responses of the gingiva under acute inflammatory conditions for several days. They found that acute psychological stress increased local proinflammatory responses [55].

A series of studies were conducted on students experiencing academic stress during examination by Deinzer et al. [56]-[59] to evaluate the effect of stress on periodontal health. They concluded that academic stress was shown to be a risk factor for gingival inflammation with increasing crevicular interleukin-1 $\beta$ levels and a diminution of the quality of the oral hygiene. In a pilot study in 1998, Axtelius (1998) [60] showed the presence of cortisol in gingival crevicular fluid.

Pindborg (1951) [61] reported that $98 \%$ of the ANUG patients were smokers and that the frequency of ANUG increased with an increasing exposure to tobacco smoke. It has not been established whether this correlation occur because:

(1) Tobacco smoking has a direct toxic effect on the gingiva

(2) Vascular or other changes are induced by nicotine or other substance

(3) Smoking and ANUG are both reflections of stress.

Cojen et al. (1983) [62] found acute necrotizing ulcerative gingivitis (ANUG) patients when compared to controls presented with

(1) Depressed PMN chemotaxis and phagocytosis and

(2) Reduced proliferation of lymphocytes upon stimulation by a nonspecific mitogen. They also suggested that depression of some host defense mechanisms, under stress conditions, might be important in the pathogenesis of ANUG.

2) Stress and Periodontitis

Acute psychological stress induces the local release of IL-8, an important proinflammatory agent and a marker of proinflammatory activity, which occurs very quickly. However, like other cytokines (e.g., IL-4 and tumor necrosis factor- $\alpha$ ), preformed IL-8 is found to be stored within the granules of various cells that can release these proteins very quickly. A rapid IL-8 release from endothelial cells has been observed within 15 minutes [63]-[71].

Page et al. (1983) [72] described aggressive periodontitis as a particular disease and established the link existing between aggressive periodontitis and psychosocial factors and loss of appetite. In a case-control study in 1996, Monteira da Silva [73] showed that people with aggressive periodontitis were more depressed and more socially isolated than people with chronic periodontitis or control group.

\subsection{Response to Periodontal Treatment}

Kamma and Baehni (2003) [8] conducted a study to evaluate the clinical and microbiological status of patients with aggressive periodontitis who had received supportive periodontal care every 3 - 6 months for a period of 5 years following active periodontal treatment. The results showed that supportive periodontal care was effective, but some sites in some patients were still progressive which can be explained by presence of variables such as Porphyromonas gingivalis, Treponema denticola, total bacterial load, number of acute episodes, number of teeth lost, smoking and stress responsible for progression of the disease. 
Genco et al. (1999) [74] evaluated relationship between psychosocial stress, coping in response to stress, and periodontal disease in a cross-sectional epidemiological study of 1426 adults, aged 25 - 74 years. The results indicated a significant role of financial strain in relation to alveolar bone loss and periodontal attachment loss, after adjusting not only for age and gender, but also for smoking. Interestingly, individuals with a problem-solving coping style for stress management fared better than those who exhibited a more emotionally focused and less adequate coping response to psychosocial strain. The pattern of results from this study suggests to the authors, quite reasonably, that effects of psychosocial stress on periodontal disease can be modulated by adequate coping behaviours.

Wimmer et al. (2005) [75] assessed the influence of coping with stress on periodontal therapy and concluded that patients with maladaptative coping strategies have more advanced disease and poor response to a non-surgical periodontal treatment. Thus maladaptative behaviours are of great importance in the medical history, treatment and maintenance of patients with periodontal disease.

\subsection{Management of Stress}

Coping against stress is the effort to try to reduce, control or tolerate the state of stress. It needs adjustment, adaptation and confrontation strategies. These coping strategies may be used in generalized stressful situations. Individuals use coping measures to reduce its intensity or to overcome stress altogether. A successful coping is when the subject has the feeling to face the stress and able to control the given situation. An unsuccessful coping is when the subject is submerged by stressor agents and is in the reaction of stress [76] (Figure 2).

\subsubsection{The International Stress Prevention Centre}

The International Stress Prevention Centre (CSPC or Community Stress Prevention Centre) was established in 1981 Kiryat Shmona, Israel. CSPC is the oldest organization in Israel that deals with the treatment and prevention of psychotrauma. It is a registered NGO which promotes stress and crisis management on National, Organizational, Community and individual levels worldwide.

\subsubsection{Stress Reduction Protocol}

The stress reduction protocol includes two series of procedures that when used either individually or collectively, act to minimize stress to the patient during treatment and thereby decrease the degree of risk presented to the patient.

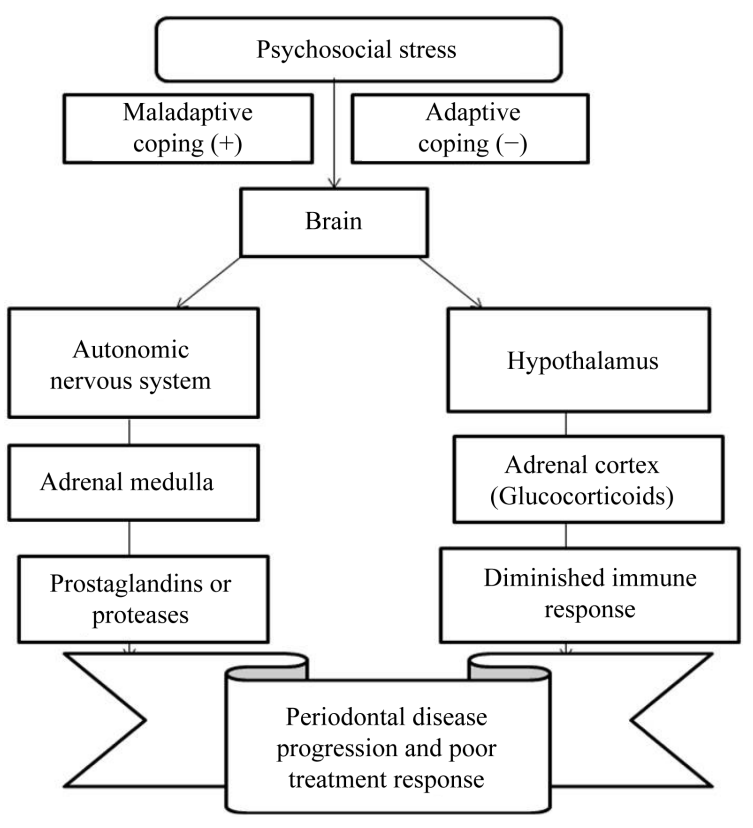

Figure 2. Effect of coping behaviour on periodontal disease progression. 
1) Stress reduction protocol for normal, healthy anxious patients. (ASA I)

2) Stress reduction protocol for medical risk patient (ASA II, III, IV)

\subsubsection{Stress Reduction Protocol in Dental Office Includes:}

1) Recognition of medical risk and anxiety.

2) Medical consultation.

3) Premedication (Antianxiety or sedative-hypnotic drugs given one night before the appointment or one hour before appointment).

4) Appointment scheduling.

5) Minimized waiting time to reduce anxiety.

6) Vital signs monitoring: BP, heart rate, rhythm and respiratory rate

7) Psychosedation.

\subsubsection{Stress Reduction by the Patient Includes}

There are several ways of coping with stress. Some techniques of time management may help a person to control stress. The Journal of the Canadian Medical Association have recently dubbed "Destressitizers" as any process by which an individual can relieve stress.

1) Regular exercise helps to burn off and use up the stress hormones and neurochemicals.

2) The benefits of meditation and other relaxation techniques for 20 to 30 minute sessions a day can have lasting beneficial effects on reducing the stress levels.

3) Elimination of drug use and not more than moderate alcohol use are key to the successful management of stress.

4) Strengthen your relationships by building a strong support network which works as greatest protection against stress. Spend time with the people you love and don't let your responsibilities keep you from having a social life.

5) Learn better ways to manage time. Think about which things are most important, and do those first.

6) Find better ways to cope. Look at how you have been dealing with stress. Be honest about what works and what does not. Think about other things that might work better.

7) Take good care of yourself. Get plenty of rest. Eat well. Don't smoke.

8) Try out new ways of thinking. When you find yourself starting to worry, try to stop the thoughts. Work on letting go of things you cannot change. Learn to say "No".

9) Speak up. Not being able to talk about your needs and concerns creates stress and can make negative feelings worse. Assertive communication can help you express how you feel in a thoughtful, tactful way.

10) Ask for help. People who have a strong network of family and friends manage stress better.

\section{Conclusion}

There is no doubt that stress has important clinical implications in periodontal disease development and also influences treatment outcomes. Identifying reliable stress-related biomarkers in saliva may eventually end up in development of chair-side tests with potential multidisciplinary applications. The dental practioner may always decide to refer patients to appropriate professional for assistance and counselling. Therefore, determining patients under chronic stress could develop specific multidisciplinary treatment strategies for ultimate effects of coping with stress factors and improvement of prognosis and outcome of periodontal treatment.

\section{References}

[1] Koolhaas, J.M., Bartolomucci, A., Buwalda, B. et al. (2011) Stress Revisited: A Critical Evaluation of the Stress Concept. Neuroscience \& Biobehavioral Review, 35, 1291-1301. http://dx.doi.org/10.1016/j.neubiorev.2011.02.003

[2] Selye, H. (1976) Stress in Health and Disease. Butterworths, Boston.

[3] Breivik, T., Thrane, P.S., Murison, R. and Gjermo, P. (1996) Emotional Stress Effects on Immunity, Gingivitis and Periodontitis. European Journal of Oral Sciences, 104, 327-334. http://dx.doi.org/10.1111/j.1600-0722.1996.tb00087.x

[4] De Marco, T. (1996) Periodontal Emotional Stress Syndrome. Journal of Periodontology, 47, 67-68. http://dx.doi.org/10.1902/jop.1976.47.2.67

[5] Leresche, L. and Dworkin, S.F. (2002) The Role of Stress in Inflammatory Disease, Including Periodontal Disease: 
Review of Concepts and Current Findings. Periodontology 2000, 30, 91-103. http://dx.doi.org/10.1034/j.1600-0757.2002.03009.x

[6] Rosania, A.E., Low, K.G., McCormick, C.M. and Rosania, D.A. (2009) Stress, Depression, Cortisol, and Periodontal Disease. Journal of Periodontology, 80, 260-62. http://dx.doi.org/10.1902/jop.2009.080334

[7] Bartold, P., Kylstra, A. and Lawson, R. (1994) Substance P: An Immunohistochemical and Biochemical Study in Human Gingival Tissues. A Role for Neurogenic Inflammation? Journal of Periodontology, 65, 1113-1121. http://dx.doi.org/10.1902/jop.1994.65.12.1113

[8] Kamma, J.J. and Baehni, P.C. (2003) Five-Year Maintenance Follow-Up of Early-Onset Periodontitis Patients. Journal of Clinical Periodontology, 30, 562-572. http://dx.doi.org/10.1034/j.1600-051X.2003.00289.x

[9] Wimmer, G., Janda, M., Wieselmann-Penkner, K., Jakse, N., Polansky, R. and Pertl, C. (2002) Coping with Stress: Its Influence on Periodontal Disease. Journal of Periodontology, 73, 1343-351. http://dx.doi.org/10.1902/jop.2002.73.11.1343

[10] Hilgert, J.B., Hugo, F.N., Bandeira, D.R. and Bozzetti, M.C. (2006) Stress, Cortisol, and Periodontitis in a Population Aged 50 Years and over. Journal of Dental Research, 85, 324-328. http://dx.doi.org/10.1177/154405910608500408

[11] Rai, B., Kaur, J., Anand, S.C. and Jacobs, R. (2011) Salivary Stress Markers, Stress, and Periodontitis: A Pilot Study. Journal of Periodontology, 82, 287-292. http://dx.doi.org/10.1902/jop.2010.100319

[12] Goyal, S., Jajoo, S., Nagappa, G. and Rao, G. (2011) Estimation of Relationship between Psychosocial Stress and Periodontal Status Using Serum Cortisol Level: A Clinico-Biochemical Study. Indian Journal of Dental Research, 22, 6-9. http://dx.doi.org/10.4103/0970-9290.79966

[13] Dhabbar, F.S. (2002) Stress-Induced Augmentation of Immune Function-The Role of Stress Hormones, Leukocyte Trafficking, and Cytokines. Brain, Behavior, and Immunity, 16, 785-798. http://dx.doi.org/10.1016/S0889-1591(02)00036-3

[14] Culshaw, S., Mcinnes, I.B. and Liew, F.Y. (2011) What Can the Periodontal Community Learn from the Pathophysiology of Rheumatoid Arthritis? Journal of Clinical Periodontology, 38, 106-113. http://dx.doi.org/10.1111/j.1600-051X.2010.01669.x

[15] Chida, Y. and Hamer, M. (2008) An Association of Adverse Psychosocial Factors with Diabetes Mellitus: A MetaAnalytic Review of Longitudinal Cohort Studies. Diabetologia, 51, 2168-2178. http://dx.doi.org/10.1007/s00125-008-1154-1

[16] Backe, E.M., Seidler, A., Latza, U., Rossnagel, K. and Schumann, B. (2012) The Role of Psychosocial Stress at Work for the Development of Cardiovascular Diseases: A Systematic Review. International Archives of Occupational and Environmental Health, 85, 67-79. http://dx.doi.org/10.1007/s00420-011-0643-6

[17] Stabholz, A., Soskolne, W.A. and Shapira, L. (2010) Genetic and Environmental Risk Factors for Chronic Periodontitis and Aggressive Periodontitis. Periodontology 2000, 53, 138-153. http://dx.doi.org/10.1111/j.1600-0757.2010.00340.x

[18] Freeman, R. and Goss, S. (1993) Stress Measures as Predictors of Periodontal Disease-A Preliminary Communication. Community Dentistry and Oral Epidemiology, 21, 176-177. http://dx.doi.org/10.1111/j.1600-0528.1993.tb00748.x

[19] Ng, S.K. and Keung Leung, W. (2006) A Community Study on the Relationship between Stress, Coping, Affective Dispositions and Periodontal Attachment Loss. Community Dentistry and Oral Epidemiology, 34, 252-266. http://dx.doi.org/10.1111/j.1600-0528.2006.00282.x

[20] Peruzzo, D.C., Benatti, B.B., Ambrosano, G.M., Nogueira-Filho, G.R., Sallum, E.A., Casati, M.Z. and Nociti, F.H. (2007) A Systematic Review of Stress and Psychological Factors as Possible Risk Factors for Periodontal Disease. Journal of Periodontology, 78, 1491-1504. http://dx.doi.org/10.1902/jop.2007.060371

[21] Rosania, A.E., Low, K.G., McCormick, C.M. and Rosania, D.A. (2009) Stress, Depression, Cortisol, and Periodontal Disease. Journal of Periodontology, 80, 260-266. http://dx.doi.org/10.1902/jop.2009.080334

[22] Ballieux, R. (1991) Impact of Mental Stress on the Immune Response. Journal of Clinical Periodontology, 18, 427-430. http://dx.doi.org/10.1111/j.1600-051X.1991.tb02311.x

[23] Linden, G.J., McKinnell, J., Shaw, C. and Lundy, F.T. (1998) Substance P and Neurokinin A in Gingival Crevicular Fluid in Periodontal Health and Disease. Journal of Clinical Periodontology, 24, 799-803. http://dx.doi.org/10.1111/j.1600-051X.1997.tb01192.x

[24] Monteiro da Silva, A., Newman, H. and Oakley, D. (1995) Psychosocial Factors in Inflammatory Periodontal Diseases. Journal of Clinical Periodontology, 22, 516-526. http://dx.doi.org/10.1111/j.1600-051X.1995.tb00799.x

[25] Buduneli, N., Ozcaka, O. and Nalbantsoy, A. (2011) Salivary and Plasma Levels of Toll-Like Receptor 2 and Toll-Like Receptor 4 in Chronic Periodontitis. Journal of Periodontology, 82, 878-884. http://dx.doi.org/10.1902/jop.2010.100467

[26] Pani, S.C., Al Askar, A.M., Al Mohrij, S.I. and Al Ohali, T.A. (2011) Evaluation of Stress in Final-Year Saudi Dental 
Students Using Salivary Cortisol as a Biomarker. Journal of Dental Education, 75, 377-384.

[27] Johannsen, A., Bjurshammar, N. and Gustafsson, A. (2010) The Influence of Academic Stress on Gingival Inflammation. International Journal of Dental Hygiene, 8, 22-27. http://dx.doi.org/10.1111/j.1601-5037.2009.00397.x

[28] Poll, E.M., Kreitschmann-Andermahr, I., Langejuergen, Y., Stanzel, S., Gilsbach, J.M., Gressner, A. and Yagmur, E. (2007) Saliva Collection Method Affects Predictability of Serum Cortisol. Clinica Chimica Acta, 382, 15-19. http://dx.doi.org/10.1016/j.cca.2007.03.009

[29] Dickerson, S.S. and Kemeny, M.E. (2004) Acute Stressors and Cortisol Responses: A Theoretical Integration and Synthesis of Laboratory Research. Psychological Bulletin, 130, 355-391. http://dx.doi.org/10.1037/0033-2909.130.3.355

[30] Groer, M., Murphy, R., Bunnell, W., Salomon, K., Van Eepoel, J., Rankin, B., White, K. and Bykowski, C. (2010) Salivary Measures of Stress and Immunity in Police Officers Engaged in Simulated Critical Incident Scenarios. Journal of Occupational \& Environmental Medicine, 52, 595-602. http://dx.doi.org/10.1097/JOM.0b013e3181e129da

[31] Kunz-Ebrecht, S.R., Mohamed-Ali, V., Feldman, P.J., Kirschbaum, C. and Steptoe, A. (2003) Cortisol Responses to Mild Psychological Stress Are Inversely Associated with Proinflammatory Cytokines. Brain, Behavior, and Immunity, 17, 373-383. http://dx.doi.org/10.1016/S0889-1591(03)00029-1

[32] Papacosta, E. and Nassis, G.P. (2011) Saliva as a Tool for Monitoring Steroid, Peptide and Immune Markers in Sport and Exercise Science. Journal of Science and Medicine in Sport, 14, 424-434. http://dx.doi.org/10.1016/j.jsams.2011.03.004

[33] Gatti, R., Antonelli, G., Prearo, M., Spinella, P., Cappellin, E. and De Palo, E.F. (2009) Cortisol Assays and Diagnostic Laboratory Procedures in Human Biological Fluids. Clinical Biochemistry, 42, 1205-1217. http://dx.doi.org/10.1016/j.clinbiochem.2009.04.011

[34] Webster Marketon, J.I. and Glaser, R. (2008) Stress Hormones and Immune Function. Cellular Immunology, 252, 1626. http://dx.doi.org/10.1016/j.cellimm.2007.09.006

[35] Hansel, A., Hong, S., Camara, R.J. and Von Kanel, R. (2010) Inflammation as a Psychophysiological Biomarker in Chronic Psychosocial Stress. Neuroscience \& Biobehavioral Reviews, 35, 115-121. http://dx.doi.org/10.1016/j.neubiorev.2009.12.012

[36] Ben-Eliyahu, S., Shakhar, G., Page, G.G., Stefanski, V. and Shakhar, K. (2000) Suppression of NK Cell Activity and of Resistance to Metastasis by Stress: A Role for Adrenal Catecholamines and Beta Adrenoceptors. NeuroImmunoModulation, 8, 154-164. http://dx.doi.org/10.1159/000054276

[37] Padgett, D.A. and Glaser, R. (2003) How Stress Influences the Immune Response. Trends in Immunology, 24, 444-448. http://dx.doi.org/10.1016/S1471-4906(03)00173-X

[38] Takai, N., Yamaguchi, M., Aragaki, T., Eto, K., Uchihashi, K. and Nishikawa, Y. (2004) Effect of Psychological Stress on the Salivary Cortisol and Amylase Levels in Healthy Young Adults. Archives of Oral Biology, 49, 963-968. http://dx.doi.org/10.1016/j.archoralbio.2004.06.007

[39] Hamaguchi, T., Fukudo, S., Kanazawa, M., Tomiie, T., Shimizu, K., Oyama, M. and Sakurai, K. (2008) Changes in Salivary Physiological Stress Markers Induced by Muscle Stretching in Patients with Irritable Bowel Syndrome. BioPsychoSocial Medicine, 2, 20.

[40] Nakane, H., Asami, O., Yamada, Y. and Ohira, H. (2002) Effect of Negative Air Ions on Computer Operation, Anxiety and Salivary Chromogranin A-Like Immunoreactivity. International Journal of Psychophysiology, 46, 85-89. http://dx.doi.org/10.1016/S0167-8760(02)00067-3

[41] Saruta, J., Tsukinoki, K., Sasaguri, K., Ishii, H., Yasuda, M., Osamura, Y.R., Watanabe, Y. and Sato, S. (2005) Expression and Localization of Chromogranin A Gene and Protein in Human Submandibular Gland. Cells Tissues Organs, 180, 237-244. http://dx.doi.org/10.1159/000088939

[42] Pradeep, A.R., Raj, S., Aruna, G. and Chowdhry, S. (2009) Gingival Crevicular Fluid and Plasma Levels of Neuropeptide Substance-P in Periodontal Health, Disease and after Nonsurgical Therapy. Journal of Periodontal Research, 44, 232-237. http://dx.doi.org/10.1111/j.1600-0765.2008.01138.x

[43] Miller, D.B. and O'Callaghan, J.P. (2002) Neuroendocrine Aspects of the Response to Stress. Metabolism-Clinical and Experimental, 51, 5-10. http://dx.doi.org/10.1053/meta.2002.33184

[44] Soell, M., Elkaim, R. and Tenenbaum, H. (2002) Cathepsin C, Matrix Metalloproteinases, and Their Tissue Inhibitors in Gingiva and Gingival Crevicular Fluid from Periodontitis-Affected Patients. Journal of Dental Research, 81, 174178. http://dx.doi.org/10.1177/154405910208100306

[45] Buduneli, N., Biyikoglu, B., Sherrabeh, S. and Lappin, D.F. (2008) Saliva Concentrations of RANKL and Osteoprotegerin in Smoker versus Non-Smoker Chronic Periodontitis Patients. Journal of Clinical Periodontology, 35, 846-852. http://dx.doi.org/10.1111/j.1600-051X.2008.01310.x

[46] Sheiham, A. and Nicolau, B. (2005) Evaluation of Social and Psychological Factors in Periodontal Disease. Periodon- 
tology 2000, 39, 118-131. http://dx.doi.org/10.1111/j.1600-0757.2005.00115.x

[47] Genco, R.J., Ho, A.W., Kopman, J., Grossi, S.G., Dunford, R.G. and Tedesco, L.A. (1998) Models to Evaluate the Role of Stress in Periodontal Disease. Annals of Periodontology, 3, 288-302. http://dx.doi.org/10.1902/annals.1998.3.1.288

[48] Ishisaka, A., Ansai, T., Soh, I., Inenaga, K., Yoshida, A., Shigeyama, C., et al. (2007) Association of Salivary Levels of Cortisol and Dehydroepiandrosterone with Periodontitis in Older Japanese Adults. Journal of Periodontology, 78, 1767-1773. http://dx.doi.org/10.1902/jop.2007.070044

[49] Johannsen, A., Rydmark, I., Soder, B. and Asberg, M. (2007) Gingival Inflammation, Increased Periodontal Pocket Depth and Elevated Interleukin-6 in Gingival Crevicular Fluid of Depressed Women on Long-Term Sick Leave. Journal of Periodontal Research, 42, 546-552. http://dx.doi.org/10.1111/j.1600-0765.2007.00980.x

[50] Giannopoulou, C., Kamma, J.J. and Mombelli, A. (2003) Effect of Inflammation, Smoking and Stress on Gingival Crevicular Fluid Cytokine Level. Journal of Clinical Periodontology, 30, 145-153. http://dx.doi.org/10.1034/j.1600-051X.2003.300201.x

[51] Mengel, R., Bacher, M. and Flores-De-Jacoby, L. (2002) Interactions between Stress, Interleukin-1Beta, Interleukin-6 and Cortisol in Periodontally Diseased Patients. Journal of Clinical Periodontology, 29, 1012-1022. http://dx.doi.org/10.1034/j.1600-051X.2002.291106.x

[52] Soeda, R., Tasaka, A. and Sakurai, K. (2012) Influence of Chewing Force on Salivary Stress Markers as Indicator of Mental Stress. Journal of Oral Rehabilitation, 39, 261-269. http://dx.doi.org/10.1111/j.1365-2842.2011.02264.x

[53] Olkinuora, M. (1972) Psychosocial Aspects in a Series of Bruxists Compared with a Group of Non-Bruxists. Suomen Hammaslääkäriseuran Toimituksia, 68, 200-208.

[54] Mercado, F.B., Marshall, R.I. and Bartold, P.M. (2003) Inter-Relationships between Rheumatoid Arthritis and Periodontal Disease. Journal of Clinical Periodontology, 30, 761-772. http://dx.doi.org/10.1034/j.1600-051X.2003.00371.x

[55] Deinzer, R., Granrath, N., Stuhl, H., Twork, L., Idel, H., Waschul, B. and Herforth, A. (2004) Acute Stress Effects on Local IL-1 $\beta$ Responses to Pathogens in a Human in Vivo Model. Brain, Behavior, and Immunity, 18, 458-467. http://dx.doi.org/10.1016/j.bbi.2003.11.008

[56] Deinzer, R., Föster, P., Fuck, L., Herforth, A., Stiller-Winkler, R. and Idel, H. (1999) Increase of Crevicular Interleukin $1 \mathrm{~b}$ under Stress at Experimental Gingivitis Sites and at Sites of Perfect Oral Hygiene. Journal of Clinical Periodontology, 26, 1-8. http://dx.doi.org/10.1034/j.1600-051X.1999.260101.x

[57] Deinzer, R., Kottman, W., Föster, P., Herforth, A., Stiller-Winkler, R. and Idel, H. (2000) After Effects of Stress on Crevicular Interleukin-1 $\beta$. Journal of Clinical Periodontology, 27, 74-77. http://dx.doi.org/10.1034/j.1600-051x.2000.027001074.x

[58] Deinzer, R., Hilpert, D., Bach, K., Schawacht, M. and Herforth, K. (2001) Effects of Academic Stress on Oral HygieneA Potential Link between Stress and Plaque Associated Disease? Journal of Clinical Periodontology, 28, 459-464. http://dx.doi.org/10.1034/j.1600-051x.2001.028005459.x

[59] Deinzer, R., Rüttermen, S., Möbes, O. and Herforth, A. (1998) Increase in Gingival Inflammation under Academic Stress. Journal of Clinical Periodontology, 25, 431-433. http://dx.doi.org/10.1111/j.1600-051X.1998.tb02467.x

[60] Axtellius, B., Edwardsson, S., Theodorsson, E., Svensater, G. and Attstrom, R. (1998) Presence of Cortisol in Gingival Crevicular Fluid. A Pilot Study. Journal of Clinical Periodontology, 25, 929-932. http://dx.doi.org/10.1111/j.1600-051X.1998.tb02392.x

[61] Pindborg, J.J. (1951) Gingivitis in Military Personnel with Special Reference to Ulceromembranous Gingivitis. Odontologisk Tidskrift, 59, 407-493.

[62] Cogen, R.B., Stevens Jr., A.W., Cohen-Cole, S., Kirk, K. and Freeman, A. (1983) Leukocyte Function in the Etiology of Acute Necrotizing Ulcerative Gingivitis. Journal of Periodontology, 54, 402-407. http://dx.doi.org/10.1902/jop.1983.54.7.402

[63] Walsh, L.J., Trinchieri, G., Waldorf, H.A., Whitaker, D. and Murphy, G.F. (1991) Human Dermal Mast Cells Contain and Release Tumor Necrosis Factor $\alpha$, Which Induces Endothelial Leukocyte Adhesion Molecule 1. Proceedings of the National Academy of Sciences of the United States of America, 88, 4220-4224. http://dx.doi.org/10.1073/pnas.88.10.4220

[64] Frangogiannis, N.G., Lindsey, M.L., Michael, L.H., Youker, K.A., Bressler, R.B., Mendoza, L.H., Spengler, R.N., Wayne Smith, C. and Entman, M.L. (1998) Resident Cardiac Mast Cells Degranulate and Release Preformed TNF- $\alpha$, Initiating the Cytokine Cascade in Experimental Canine Myocardial Ischemia/Reperfusion. Circulation, 98, 699-710. http://dx.doi.org/10.1161/01.CIR.98.7.699

[65] Spencer, L.A., Melo, R.C.N., Perez, S.A.C., Bafford, S.P., Dvorak, A.M. and Weller, P.F. (2006) Cytokine Receptor Mediated Trafficking of Preformed IL-4 in Eosinophils Identifies an Innate Immune Mechanism of Cytokine Secretion. 
Proceedings of the National Academy of Sciences of the United States of America, 103, 3333-3338. http://dx.doi.org/10.1073/pnas.0508946103

[66] Oynebraten, I., Bakke, L., Brandtzaeg, P., Johansen, F.E. and Haraldsen, G. (2004) Rapid Chemokine Secretion from Endothelial Cells Originates from 2 Distinct Compartments. Blood, 104, 314-320. http://dx.doi.org/10.1182/blood-2003-08-2891

[67] Bandeira-Melo, C., Sugiyama, K., Woods, L.J. and Weller, P.F. (2001) Cutting Edge, Eotaxin Elicits Rapid Vesicular Transport-Mediated Release of Preformed IL-4 from Human Eosinophils. Journal of Immunology, 166, 4813-4817.

[68] Gibbs, B.F., Wierecky, J., Welker, P., Henz, B.M., Wolff, H.H. and Grabbe, J. (2001) Human Skin Mast Cells Rapidly Release Preformed and Newly Generated TNF-Alpha and IL-8 Following Stimulation with Anti-IgE and Other Secretagogues. Experimental Dermatology, 10, 312-320. http://dx.doi.org/10.1034/j.1600-0625.2001.100503.x

[69] Gibbs, B.F., Haas, H., Falcone, F.H., Albrecht, C., Vollrath, I.B., Noll, T., Wolff, H.H. and Amon, U. (1996) Purified Human Peripheral Blood Basophils Release Interleukin-13 and Preformed Interleukin-4 Following Immunological Activation. European Journal of Immunology, 26, 2493-2498. http://dx.doi.org/10.1002/eji.1830261033

[70] Schröder, A.K., Uciechowski, P., Fleischer, D. and Rink, L. (2006) Crosslinking of CD66b on Peripheral Blood Neutrophils Mediates the Release of Interleukin-8 from Intracellular Storage. Human Immunology, 67, 676-682. http://dx.doi.org/10.1016/j.humimm.2006.05.004

[71] Utgaard, J.O., Jahnsen, F.L., Bakka, A., Brandtzaeg, P. and Haraldsen, G. (1998) Rapid Secretion of Prestored Interleukin-8 from Weibel-Palade Bodies of Microvascular Endothelial Cells. Journal of Experimental Medicine, 188, 1751-1756. http://dx.doi.org/10.1084/jem.188.9.1751

[72] Page, R.C., Altman, L.C., Ebersole, J.L., Vandesteen, G.E., Dahlberg, W.H., Williams, B.L. and Osterberg, S.K. (1983) Rapidly Progressive Periodontitis: A Distinct Clinical Condition. Journal of Periodontology, 54, 197-209. http://dx.doi.org/10.1902/jop.1983.54.4.197

[73] Monteira da silva, A., Oakley, D., Newmann, H., Nohl, F. and Lloyd, H.M. (1996) Psychosocial Factors and Adult Onset Rapidly Progressive Periodontitis. Journal of Clinical Periodontology, 23, 789-794. http://dx.doi.org/10.1111/j.1600-051X.1996.tb00611.x

[74] Genco, R.J., Ho, A.W., Grossi, S.G., Dunford, R.G. and Tedesco, L.A. (1999) Relationship of Stress, Distress and Inadequate Coping Behaviors to Periodontal Disease. Journal of Periodontology, 70, 711-723. http://dx.doi.org/10.1902/jop.1999.70.7.711

[75] Wimmer, G., Köhldorfer, G., Mischak, I., Lorenzoni, M. and Kallus, K.W. (2005) Coping with Stress: Its Influence on Periodontal Therapy. Journal of Periodontology, 76, 90-98. http://dx.doi.org/10.1902/jop.2005.76.1.90

[76] Reners, M. and Brecx, M. (2007) Stress and Periodontal Disease. International Journal of Dental Hygiene, 5, $199-204$. http://dx.doi.org/10.1111/j.1601-5037.2007.00267.x 